\title{
Baralha e volta a dar
}

\author{
Rui Aires Augusto
}

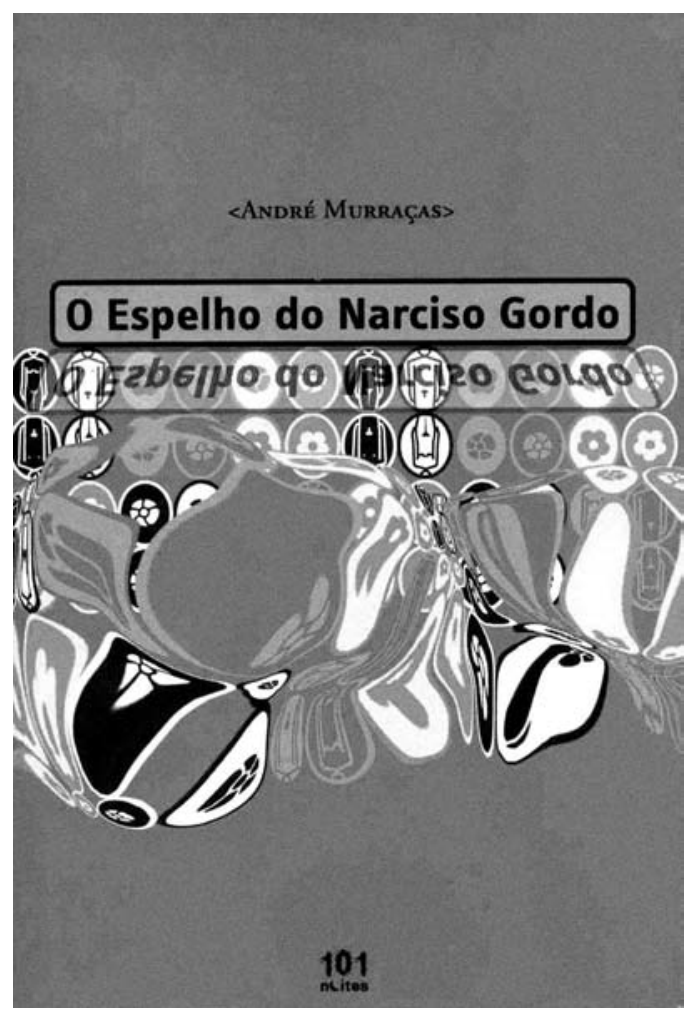

Levado por uma vaga sugestão do trabalho de André Murraças, mais como intérprete e cenógrafo, a minha primeira preocupação ao preparar uma recensão a este seu livro foi ter notícia de espectáculos que pudesse ter ocasionado. Para minha surpresa, até agora nenhum. Aguarda subsídio para representação, situação em que o autor seria o encenador e actor, talvez acompanhado por Anabela Brígida e Afonso Melo', reunindo assim o grupo que no Op Art de Alcântara, em Agosto de 2003, divulgou o texto em leitura encenada ${ }^{2}$.

Tendo sido proposto para o "Prémio de execução (original)" do concurso "Teatro na Década 2003", O espelho do Narciso gordo foi, afinal, distinguido na categoria "Texto (original)". Coube ao CPAl - Centro Português de Artes e Ideias, associação organizadora daquele evento, encetar uma parceria com a chancela 101 Noites para a publicação do texto em 2003.

Ao considerarmos o trabalho de André Murraças como agente do teatro português contemporâneo, tendo em conta a linha programática dos seus espectáculos, como por exemplo As peças amorosase Swingers, em que a palavra é um acessório na centralização da criação no corpo do performer ostentado ${ }^{3}$, parece ficar por cumprir essa mesma urgência de performatividade que por ora está apenas proposta e encarcerada na palavra escrita.

\author{
André Murraças, $O$ espelho do Narciso \\ gordo, Lisboa, 101 Noites, 2003, 62 pp.
}

Não que o texto perca a sua validade em impresso e se conforme apenas a um estatuto de guião insipido. Isso não acontece até porque dá azo a algumas abordagens, digamos, fundamentais no estudo da dramaturgia portuguesa contemporânea. Logo à primeira vista, e isto é já um clássico, veja-se a sua estruturação harmónica de montagem e a disrupção total da fábula que, estilhaçada, apenas é recuperada em fragmentos que se correspondem através de um dispositivo de repetição e/ou variação. A abordagem a um texto com estas características faz-se através de uma leitura de pormenor, atenta a uma elaborada rede de implicações entrevista muito mais ao nivel da estrutura, no entrelaçado dos episódios. Dai a dificuldade de fazer figurar nestas linhas um resumo da acção.

Com efeito, essa dimensão de montagem é agudizada pela impossibilidade de organização ou reconstituição temporal, o que penaliza a construção macro-estrutural de uma acção congregante, já não digo una. Ela escapa para um acumulado de situações, de episódios que confluem em espiral para formar um sentido que thes está na base. Precisamente, esse sentido é retirado aquando da confrontação entre um episódio inicial e a sua evolução num episódio procedente, em que a incisão, a elisão, ou a variação ou avanço, dão significação ao texto rumo a uma orientação temática, a par de outros episódios singulares - e significantes por si só - que abrem brechas nessa estrutura.

Não pretendo fazer um levantamento exaustivo dessas situações, mas quero assinalar aqui alguns casos que corroboram esta leitura. Antes de mais, considere-se a estrutura externa do texto organizada em 3 "blocos", donde se pode inferir uma dinâmica similar a 3 actos (apresentação > nó > desenlace/sintese). A recuperação de episódios precedentes dos blocos 1 e 2 é orientada por uma variação desses episódios no $3^{\circ}$ bloco que lhes acrescenta significado. Tanto a quantidade como a qualidade dessa variação é que são apresentadas em diferentes moldes, não deixando de construir uma simetria calculada, para o que contribui o equilibrio da distribuição dos episódios pelos três blocos. Contabilizando-os, chegamos a esta fórmula: $10+1$ no $1^{\circ}$ bloco, 13 no $2^{\circ} \mathrm{e}$ 11+1 no $3^{\circ}$, sendo os episódios soltos nos blocos 1 e 3 uma espécie de entremezes sem discurso, incrustados no texto para garantir a ligação e uma cesura que marca o início da variação entre episódios.

Do 10 bloco são recuperados 7 episódios quase integralmente, operando neles pequenas variações como
${ }^{1}$ Na verdade, Afonso Melo esteve na ocasião a

substituir, por

impedimento, André Amálio. 0 último, a acontecer o espectáculo, será a primeira escolha no elenco de actores.

${ }^{2}$ Dando exclusividade à representação total e profissional, é negado aqui o interesse pela representação parcial, como exercício final, dos alunos do $2^{\circ}$ ano da Escola Superior de Teatro e Cinema, dirigidos por Álvaro Correia, em Junho de 2004.

${ }^{3}$ Note-se o caso de Pour Homme, último espectáculo de André Murraças, que agudiza muito mais essa tendência ao ponto de abstrair a linguagem como forma de conferir significado. 
a supressão ou inserção de pequenos fragmentos. Como exemplo, sugiro os episódios "Dolly Parton diz" em que são acrescentados pequenos comentários irónicos que deslocalizam o contexto do que foi dito anteriormente. Mas mais significativa é a versatilidade do corpo que assume os papéis, a inversão do género masculino/feminino na formulação do discurso, assumindo um valor - mais do que de não pertença - de transformação.

No $2^{\circ}$ bloco e na passagem deste para o $3^{\circ}$ há outra qualidade de variação. Sendo o $2^{\circ}$ bloco o nó, é ai assumido o eixo do turbilhão: a variação é aí apresentada como uma estratégia que oferece uma fórmula para ser condicionada a propostas que a transformam, ou, na passagem do $2^{\circ}$ bloco para o $3^{\circ}$, a variação conhece um impeto de continuação - ou de aproveitamento - de uma situação inicial que dispara para outra possibilidade. Vejase, neste caso, a cena 10 do $3^{\circ}$ bloco que aproveita uma situação aventada na cena 12 do $2^{\circ}$ bloco para a concretizar em vez daquela: "Eu diria que: se os dois tivessem passado mais tempo a descobrir as maravilhas que poderiam fazer um ao outro e o prazer que dai poderiam tirar, a vida inocente de uma criança teria sido poupada." (p.50). Será isso que virá a acontecer no $3^{\circ}$ bloco, na página 60 , em que é relatado o ímpeto de mutilação e antropofagia a que se entregam Leopold e Loeb, finalmente descobrindo "as maravilhas que poderiam fazer um ao outro".

Esta estruturação do texto acrescenta-Ihe um efeito de hipótese, de transformação dos dados iniciais, de
${ }^{4}$ A este propósito, vejam-se as pp. 19-20 e 57-58 de 0 espelho do Narciso

${ }^{5}$ Poema de Cavafy referido na "Carta de Andre Murraças a Oscar Wilde em jeito de prefácio", in 0 espelho do narciso gordo, versatilidade, tanto mais que a sua significação é ampliada pela desindividualização e desmultiplicação das personagens. De facto, se aparentemente o texto se conformava a um registo discursivo de relato, de confissão de experiências, monologado ou dialogado, dando toda a impressão de eco, ou até de formatação do discurso, a desvinculação da personagem a um discurso singular cumpre uma estratégia mais de estranhamento ou desadequação do corpo enunciador; isto é, se é possivel dizê-lo assim, do "corpo textual" da personagem, perfeitamente identificada no seu género masculino/feminino (Ele 1, Ele 2, Ela), que actualiza papéis estranhos a essa identificação.

Estando sobrepostos dois niveis de ficção (e a execução do texto poderia muito mais acentuar as variações previstas e a dupla máscara do enunciador do discurso), a personagem é desmultiplicada, não só nos diferentes papéis que lhe cabem e na simultaneidade ou alternância desses papéis, mas também nos dois planos em que é exposta como signo, como ícone, e como enunciador ou manipulador dos papéis. No mesmo sentido, a desindividualização da personagem constrói-se pela impossibilidade de ser identificada com um papel, com um género, logo por uma total incapacidade de correspondência verosímil.

Já essa estratégia vinha anunciada no título e no texto pelas efabulações da obsessão da imagem: imagem desvirtuada, ou melhor, virtual, não auto-reflexiva, mas construída, elaborada por formatação do discurso e da pose/gesto, que, se preconiza uma representação normativa, um modelo de representação, dispersa em tudo o mais uma identificação com o que é pré-existente e que se assemelha a uma construção artificial. 0 "Narciso gordo" assegura o modelo da sua representação, das suas transformações, sobrepondo-Ihe um modelo referencial entrevisto num espelho, já de si deveras multifacetado, que lhe garante a sua habilidade para o travestimento e Ihe devolve, como as várias faces do poliedro, uma identidade múltipla sem chegar a ser fragmentada.

A duplicidade subjacente a esta estratégia revela uma outra pela conformação do texto a um exercício programático de representação anti-normativa, de conceptualização versátil da identidade, do género, da sexualidade, enfim, o engajamento com os gender studies. Então, todas as variações e transformações presentes atendem a um princípio de desformatação > nova formatação, pela busca de uma identidade que possa adequar a personagem ao seu papel sem produzir estranheza, para que esse espelho a que se observa obsessivamente aceite a construção de um corpo - "Remember, body...". 